\title{
Right ventricle-pulmonary circulation dysfunction: a review of energy-based approach
}

Namheon Lee ${ }^{1,2}$, Michael D Taylor $^{1}$, Rupak K Banerjee ${ }^{2^{*}}$

\author{
* Correspondence: Rupak. \\ Banerjee@uc.edu \\ ${ }^{2}$ The Department of Mechanical \\ and Materials Engineering, \\ University of Cincinnati, $\mathrm{OH}, 45221$, \\ USA
}

\begin{abstract}
Patients with repaired or palliated right heart congenital heart disease (CHD) are often left with residual lesions that progress and can result in significant morbidity. However, right ventricular-pulmonary arterial evaluation and the timing of reintvervention is still subjective. Currently, it relies on symptomology, or RV imaging-based metrics from echocardiography or MR derived parameters including right ventricular (RV) ejection fraction (EF), end-systolic pressure (ESP), and end-diastolic volume (EDV). However, the $\mathrm{RV}$ is coupled to the pulmonary vasculature, and they are not typically evaluated together. For example, the dysfunctional right ventricular-pulmonary circulation (RV-PC) adversely affects the RV myocardial performance resulting in decreased efficiency. Therefore, comprehensive hemodynamic assessment should incorporate changes in RV-PC and energy efficiency for CHD patients.

The ventricular pressure-volume relationship (PVR) and other energy-based endpoints derived from PVR, such as stroke work (SW) and ventricular elastance $\left(E_{e s}\right)$, can provide a measure of RV performance. However, a detailed explanation of the relationship between RV performance and pulmonary arterial hemodynamics is lacking. More importantly, PVR is impractical for routine longitudinal evaluation in a clinical setting, because it requires invasive catheterization. As an alternative, analytical methods and computational fluid dynamics (CFD) have been used to compute energy endpoints, such as power loss or energy dissipation, in abnormal physiologies.

In this review, we review the causes of RV-PA failure and the limitation of current clinical parameters to quantify RV-PC dysfunction. Then, we describe the advantage of currently available energy-based endpoints and emerging energy endpoints, such as energy loss in the Pas or kinetic energy, obtained from a new non-invasive imaging technique, i.e. 4D phase contrast MRI.
\end{abstract}

\section{Introduction}

Congenital heart diseases (CHDs) often lead to critical conditions causing morbidity, mortality, and increased healthcare cost for patients during their treatment period, which often begins from childhood. The recently reported incidence of CHD in the United States is approximately 8 per 1000 live births [1]. From 1940 to 2002, about 2 million patients with CHD were born in the Unites State [2], ranging in severity from simple pinholes between heart chambers to major defects, which require consecutive surgical interventions during childhood.

Recent advances in diagnosis and surgical treatments for CHD patients significantly reduce (less than $2 \%$ ) the early postoperative mortality rate [3]. However, the late postoperative morbidity rate remains still high. In the third decade after the repair surgery,

(c) 2015 Lee et al.: licensee BioMed Central Ltd. This is an Open Access article distributed under the terms of the Creative Commons Attribution License (http://creativecommons.org/licenses/by/4.0), which permits unrestricted use, distribution, and reproduction in any medium, provided the original work is properly cited. The Creative Commons Public Domain Dedication waiver (http:// creativecommons.org/publicdomain/zero/1.0/) applies to the data made available in this article, unless otherwise stated. 
the mortality rate for certain surgeries is approximately $30 \%$, and the morbidity rate is higher still $[4,5]$. CHDs associated with the right heart, including tetralogy of Fallot, double outlet right ventricle, transposition of the great arteries, and aortic valve stenosis requiring pulmonary valve homograft, account for $25 \%$ to $35 \%$ of the total CHD. The primary cause of increased late postoperative morbidity and mortality rate is the post-operative sequelae, i.e. RV-PA circulation (RV-PC) dysfunction and residual RV outflow tract obstruction. The residual lesions, such as pulmonary regurgitation, result in RV dilatation causing various degrees of RV myocardial dysfunction, arrhythmias, LV dysfunction, and occasionally sudden death [6-13].

In the clinical setting, cardiac magnetic resonance imaging (MRI), including 2D phase contrast MR imaging, and catheterization have been used as gold standards to assess systolic and diastolic ventricular volumes, flow, and pressure. However, these techniques are limited by the fact that 1) 2D phase contrast MRI allows only the 1D axial flow information through a prospectively chosen plane and 2) catheterization is invasive and is not considered as a routine evaluation modality for longitudinal follow-up.

To circumvent these obstacles, energy-based endpoints have been proposed. Such end-points will be discussed in the following sections. Energy-based endpoints are believed to be superior indicators in assessing the status of ventricular hemodynamic status over current techniques, including echocardiography, cardiac MRI, and catheterization, when used independently $[14,15]$. Energy endpoints, for instance ventricular stroke work (SW) and efficiency and energy loss, can combine multiple hemodynamic measurements, such as ventricular volume, pulmonary flow, and pressure data, into a single parameter.

The functional assessment of right heart including the pulmonary vasculature has been less intensively studied since the result of right heart failure was thought to be less important for patient outcomes. Also, the RV operates at lower pressures compared to the left ventricle (LV) and the systemic arteries. The lower working pressure of the RV is a result of a pulmonary vascular resistance that is lower than the systemic vascular resistance because the pulmonary system has larger peripheral vessels with shorter and relatively more distensible arteries and veins.

In this review, we first describe the cause of RV-PC dysfunction followed by the importance of its long-term patient care. Secondly, we examine the advantages and limitations of current clinical diagnostic parameters in assessing abnormal hemodynamics in CHD patients. Thirdly, we discuss existing energy-based endpoints (Table 1) for evaluating extent of severity of CHD in patients. Lastly, the newer energy-based endpoints, such as energy loss and (turbulent) kinetic energy, derived from an emerging non-invasive technique, i.e., 4D phase contrast MRI, are presented.

\section{Right ventricular-pulmonary circulation dysfunction}

The RV-PC dysfunction is a post-operative sequela of repaired CHD that patients are confronted with aging. Typically, it involves one or more of the following: 1) pulmonary regurgitation due to an absent of incompetent pulmonary valve, 2) pulmonic stenosis, 3) RV outflow tract obstruction within the RV chamber, and 4) pulmonary artery stenosis. It leads to increased RV work to maintain sufficient pulmonary circulation, resulting in the RV and PA dilatation, and progressive RV dysfunction [16-18]. Pulmonary valve replacement or repair needs to be performed before irreversible dysfunction occurs. The 
Table 1 Comparison of registration results (see Figures $7 \& 8$ ) by different values of parameter $\lambda_{2}\left(\lambda_{1}=5, \lambda_{3}=1\right)$ based on the proposed method

\begin{tabular}{cccccc}
\hline \multirow{2}{*}{ methods category } & \multicolumn{4}{c}{ performance evaluation } \\
\cline { 2 - 6 } without MMBs & $\lambda_{2}=1 \mathrm{e}-4$ & 0.0874 & 21.1311 & 0.3145 & 0.0605 \\
\cline { 2 - 5 } & $\lambda_{2}=1 \mathrm{e}-2$ & 0.0887 & 21.0074 & 0.3060 & 0.0618 \\
\cline { 2 - 6 } & $\lambda_{2}=1$ & 0.0915 & 20.7375 & 0.3111 & 0.0624 \\
\cline { 2 - 6 } & $\lambda_{2}=1 \mathrm{e}+2$ & 0.0843 & 21.4505 & 0.3100 & 0.0629 \\
\cline { 2 - 6 } & $\lambda_{2}=1 \mathrm{e}+4$ & 0.0852 & 21.3619 & 0.3075 & 0.0661 \\
\hline with MMBs & $\lambda_{2}=1 \mathrm{e}-4$ & 0.0511 & 25.7932 & 0.4004 & 0.0811 \\
\cline { 2 - 6 } & $\lambda_{2}=1 \mathrm{e}-2$ & 0.0514 & 25.7391 & 0.3995 & 0.0806 \\
\cline { 2 - 6 } & $\lambda_{2}=1$ & 0.0515 & 25.7226 & 0.4090 & 0.0815 \\
\cline { 2 - 6 } & $\lambda_{2}=1 \mathrm{e}+2$ & 0.0435 & 27.1892 & 0.5303 & 0.0803 \\
\cline { 2 - 6 } & $\lambda_{2}=1 \mathrm{e}+4$ & 0.0483 & 26.2765 & 0.4545 & 0.0827 \\
\hline
\end{tabular}

timing is important because any repair or replacement has a finite lifetime, and a younger patient may need further interventions if it is performed too early. Currently, the valves, conduits, and patches used for repair and replacement degrade over time and do not grow as a patient grows [11]. Therefore, continuous monitoring of the abnormal hemodynamic and energy status is crucial to determine the right timing for reintervention.

\section{Hemodynamic assessment using current cardiac endpoints}

With rapid development of magnetic resonance imaging (MRI) technology including both pulse sequences and MR hardware, cardiac MRI has been employed as a gold standard to diagnose RV-PA vasculature status in CHD patients [6,19-25]. RV volume-based indices obtained from cardiac MRI, such as RV ejection fraction (EF), end-diastolic and end-systolic volumes (EDV and ESV, respectively), RV mass, and peak ejection and filling rate, have been used to assess the status of RV and pulmonary vasculature [26]. Particularly, Pavlicek et al. [27] stratified 223 subjects in their study using RV EF: normal RV EF ( $\geq 50 \%$ ), moderately reduced RV EF (between $30-49 \%$ ), and severely reduced RV $\mathrm{EF}(\leq 30 \%)$. They performed both cardiac MRI and echocardiography for all subjects to assess the right ventricular systolic function and compared the results between cardiac

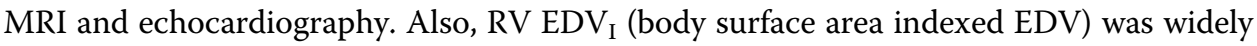
used to decide the timing for pulmonary valve replacement repair. Therrien et al., 2005 [11] suggested a cutoff value that is $170 \mathrm{ml} / \mathrm{m}^{2}$ of $\mathrm{RV} E D V_{\mathrm{I}}$ for reintervention. Their

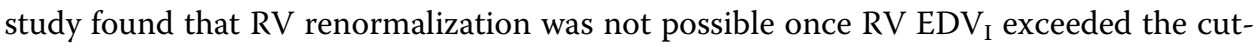
off value of $170 \mathrm{ml} / \mathrm{m}^{2}$.

The RV pressure-based parameters are also used to determine the right timing for intervention for residual obstruction. According to the ACC/AHA guidelines by Warnes et al. [28], the cutoff value of $50 \mathrm{mmHg}$ was recommended for the RV end-systolic pressure (ESP). Also, they recommended a cutoff value of 0.7 for RV/LV ESP ratio for surgical interventions, such as pulmonary valve replacement repair, balloon angioplasty, and percutaneous pulmonary valve implantation [29,30], to alleviate RV pressure overloading in CHD patients with severe RV-PC dysfunction. They reported that the possibility of irreversible RV myocardial dysfunction was increased if RV/LV ESP ratio exceeded 0.7.

Some patients with repaired RV heart disease have no outflow tract obstruction and are left with purely regurgitation as their residual lesion. Patients have RV volume 
overloading due to RV-PC dysfunction after the repair, while RV pressure level progressively increases as RV-PC dysfunction worsens with age. For example, in recent studies by Lee et al. [14,15], RV EDV $\mathrm{I}_{\mathrm{I}}$ for the CHD patients did not correlated with RV ESP. In Figure 1 the control group had a negative correlation between EDV $_{\mathrm{I}}$ and ESP $(r=-0.46 ; p<0.4)$, whereas, the patient group showed a much weaker correlation between $\mathrm{EDV}_{\mathrm{I}}$ and ESP. It is evident that the CHD patients with similar RV volume loading can have a variety of RV pressure loads. Consequently, either RV volume or pressure measurements alone may not be adequate to delineate RV-PC dysfunction for $\mathrm{CHD}$ patients. Hence, there is a need for a comprehensive clinical diagnostic endpoint that can incorporate the ventricular volume, pressure, and PA flow information, to better assess change in abnormal RV-PA hemodynamics due to RV-PC dysfunction in CHD patients.

\section{Energy-based analysis: ventricular pressure-volume relationship (PVR) Starling's Law of the heart}

Otto Frank first recognized the characteristics of ventricular pressure-volume diagram in 1899 [31]. Subsequently, in 1910s, Starling described the importance of the ventricular pressure-volume relationship, known as "Frank-Starling relationship" or "Starling's Law of the Heart" [32,33]. In general, Starling's Law states that the increase in blood volume induces the ventricular wall stretch, which affects the contractility of cardiac muscle. The stroke volume (SV, the difference between the end-diastolic and endsystolic volume) can increase when cardiac muscle has high contractility, independent of the end-diastolic volume.

In the 1940s Bing et al. [34] suggested that there is a close relationship between the ventricular systolic function, which is dependent on heart rate or contractility, and myocardial oxygen consumption $\left(\mathrm{MVO}_{2}\right)$. This is because the heart relies on the aerobic oxidation of cardiac muscle for energy generation. Afterward, many researchers used this conceptual idea to assess the ventricular work and the pumping efficiency.

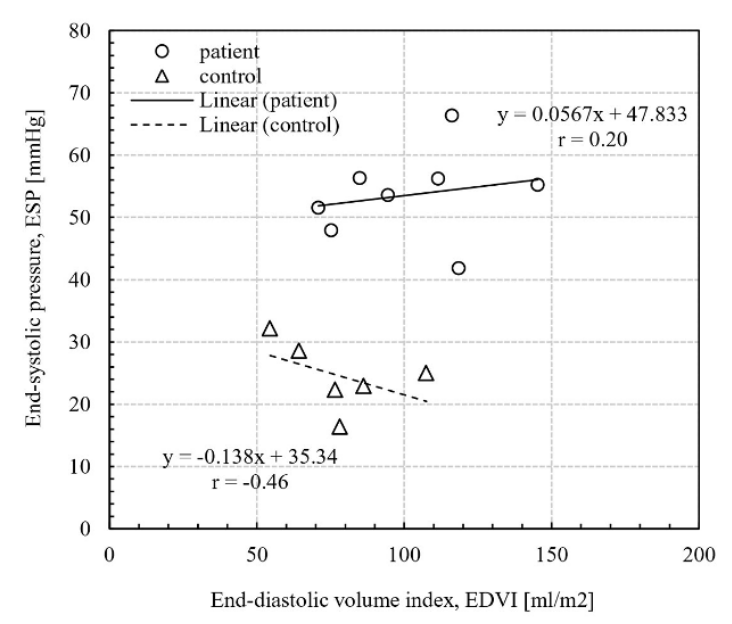

Figure 1 Correlations between end-systolic pressure (ESP) and end-diastolic volume index (EDV $)$ No correlation was observed between ESP and EDV in the patient group, whereas the control group had a weak negative correlation between ESP and EDV $(r=-0.46 ; p<0.4)$. [15] 


\section{Ventricular pressure-volume relationship (PVR)}

In line with Starling's Law, the ventricular pressure-volume relationship (PVR) has been widely accepted in evaluating ventricular performance and efficiency [35-40]. The pivotal studies using the end-systolic and diastolic pressure-volume relationships (ESPVR and EDPVR, respectively) were conducted by Suga et al. $[37,39,41,42]$ in 1970s. Conceptually, they showed that the ventricular contractility, which plays a key role in evaluating RV performance, can be obtained from the ventricular end-systolic elastance $\left(E_{e s}\right)$ using the end-systolic pressure-volume relationship (ESPVR) [42]. The $E_{e s}$ can be calculated from the slope of ESPVR curve because the ESPVR changes linearly, independent of afterload conditions (Figure 2A). As shown in Figure 2B, $E_{e s}$ calculated at a fixed preload condition has the same value as the one obtained by reducing filling volume for a fixed afterload condition (Figure 2A) [19]. With the development of isolated blood-perfused heart methodology [39], the concept of $E_{e s}$ rapidly expanded to human studies using echocardiography $[43,44]$. However, a majority of studies focus on the LV, not the RV.

\section{Ventricular stroke work and the efficiency}

Suga et al. [41,42] introduced the time varying elastance heart model and obtained the total mechanical energy of the heart by calculating the area enclosed by pressurevolume loop. They showed that the total mechanical energy had a linear relationship with myocardial oxygen consumption $\left(\mathrm{MVO}_{2}\right)$ under various loading conditions. In 1977, Baxley [45] used the Eq. 1 (given below) proposed by Bing [34] and showed an imbalance in $\mathrm{MVO}_{2}$ and the LV function in 38 patients with various CHD diseases such as aortic and mitral valve stenosis, and severe aortic and mitral regurgitation.

$$
\text { Efficiency }=\frac{L V S W}{\text { Total } \mathrm{MVO}_{2} \times 2.059} \times 100
$$

In the above equation, LV stroke work (SW) was calculated by multiplying stroke volume (SV) and mean LV pressure. The total $\mathrm{MVO}_{2}$ was computed as LV mass/100g multiplies by $\mathrm{MVO}_{2} / 100 \mathrm{~g}$, while $\mathrm{MVO}_{2} / 100 \mathrm{~g}$ value was obtained using the nitrous
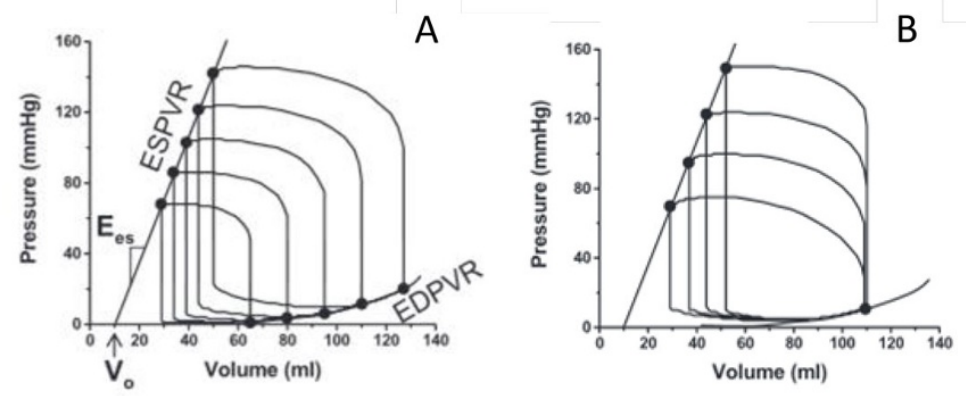

Figure 2 A) At a fixed ventricular afterload pressure, the decrease in ventricular filling pressure results in shifting of the P-V loops towards lower volumes at both the end-systole/diastole phase. $E_{\text {es, }}$ a slope of pressure and volume, and $\mathbf{V}_{\mathbf{o}}$ can be characterized by the linear end-systolic pressure-volume relationship (ESVPR). On the other hand, the non-linear end-diatolic pressure-volume relationship (EDPVR) was obtained. B) the P-V loops become longer and thinner when ventricular afterload increases at a fixed preload pressure [19]. 
oxide washout technique. The energy equivalent for $\mathrm{O}_{2} / \mathrm{ml}$ was $2.059 \mathrm{~kg} . \mathrm{m}$. Further, De Tombe et al. [46] confirmed that the peak LV SW and the efficiency $\left(=\mathrm{SW} / \mathrm{MVO}_{2}\right)$ occurred at the nearly same time. However, invasive catheterization is required to obtain the pressure data for calculating these endpoints, and thus limits the applicability of SW and efficiency analysis in the longitudinal monitoring of human subjects.

Further refinement of the efficiency calculation requires a more accurate measure of myocardial metabolism. A non-invasive measurement of myocardial metabolism can be made using positron emission tomography (PET) imaging. Porenta et al. [47] used C-11 acetate PET imaging (Figure 3) to derive oxygen consumption from the slope of the ${ }^{11} \mathrm{C}$-clearance curve recorded during myocardial washout. They modified Eq. 1 to compute mechanical efficiency of the LV as shown in Eq. 2.

$$
\text { Efficiency }=\frac{\mathrm{MAP} \times \mathrm{SV} \times \mathrm{HR} \times 1.33 \times 10^{-4}}{\mathrm{MVO}_{2} \times \mathrm{LVM} \times 20}
$$

where MAP $=$ the mean arterial pressure, $H R=$ heart rate, and LVM $=$ LV mass. They found that mechanical efficiency in 11 normal subjects was not significantly different between at the rest and stress conditions $(29 \pm 6 \%$ at rest and $32 \pm 6 \%$ during dobutamine stress). However, external work efficiency was significantly lower at rest $(16 \pm 6 \%)$ compared to dobutamine stress condition $(21 \pm 4 \%)$.

As discussed above, most studies on the ventricular SW and the efficiency were performed for the LV, and only a few studies have described the RV SW and the efficiency $[14,15,48-50]$. This is because the importance of RV performance has been underappreciated. The RV operates under lower pressure conditions compared to LV
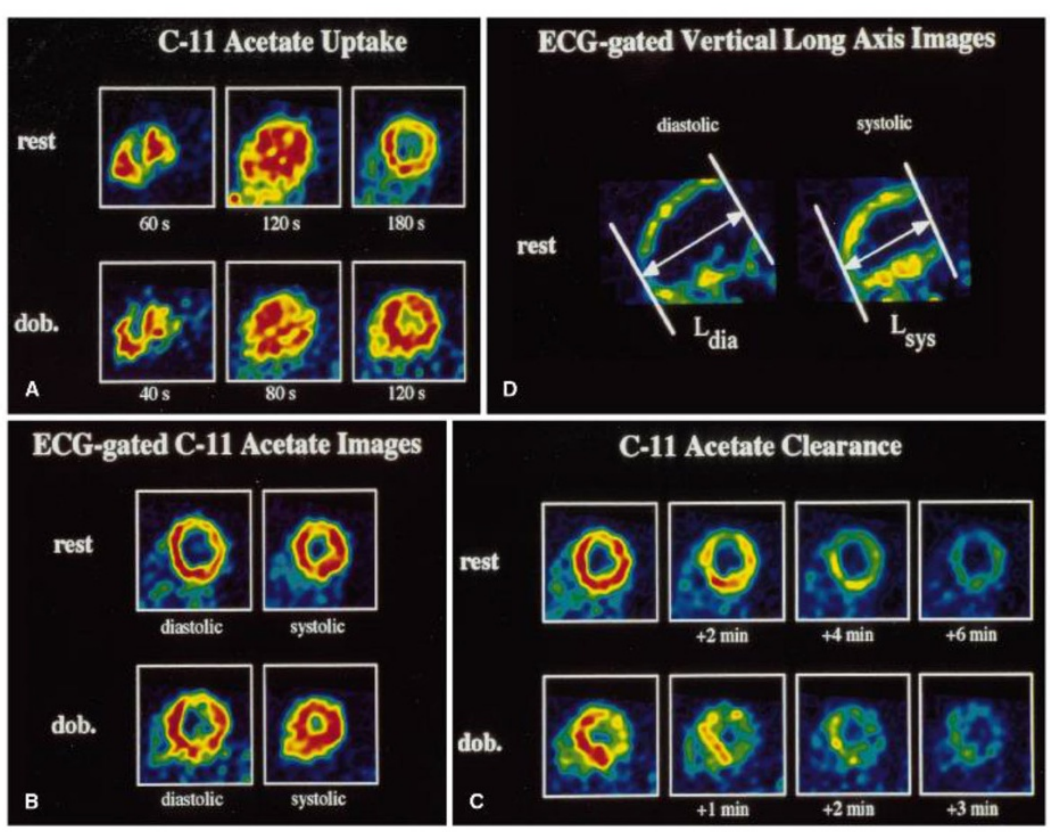

Figure 3 PET sequence in a midventricular short axis at rest and dobutamine stress. A) images with ${ }^{11} \mathrm{C}$ acetate uptake to estimate myocardial perfusion, B) ECG-gated images to estimate myocardial oxygen consumption. C) The elapsed time after tracer injection was shown under each image. D) The vertical long axis images at both the systolic and diastolic phases [47]. 
and, further, it is difficult to measure RV volume data due to its shape and eccentric movements. The RV has a crescent type twisting shape unlike the LV [51].

Recently, Das et al. [49] proposed a methodology to assess RV SW and the mechanical efficiency, energy transfer ratio $\left(e_{M P A}\right)$, using non-simultaneously acquired RV pressure, volume, and blood flow data, as follows. RV SW was calculated from RV pressure and volume synchronized by ECG gating (Eq. 3):

$$
\mathrm{RVSW}=\iint_{A} P d V=\frac{1}{2} \oint_{C}(P d V-V d P)
$$

where $P$ is RV pressure, $V$ is RV volume. The rate of energy transfer at the main PA (MPA) was computed using Eq. 4:

$$
\text { Energy transfer rate }(\dot{E})=\iint_{A}\left(p_{m}+\frac{1}{2} \rho \vec{u}_{m} \cdot \vec{u}_{m}\right) \vec{u}_{m} \cdot \mathrm{n} d A_{m}
$$

where $p_{m}$ is the MPA pressure, $\vec{u}_{m}$ is blood velocity at the MPA, and $A_{m}$ is MPA area. Finally, energy transfer ratio $\left(e_{M P A}\right)$ was obtained by a ratio of net energy transfer at the MPA $\left(E_{n e t}\right)$ to RV SW (Eq. 5):

$$
\text { Energy transfer ratio }\left(e_{M P A}\right)=\frac{E_{n e t}}{R V S W}
$$

where the net energy transfer at the MPA was computed by integration of energy transfer rate ( $\dot{E}$, Eq. 4 ) over the cardiac cycle (T). In their pilot study, the patient with tetralogy of Fallot had lower RV stroke work (patient: $0.078 \mathrm{~J} / \mathrm{s}$ vs. control: $0.115 \mathrm{~J} / \mathrm{s}$ ), and lower energy transfer at the MPA (patient: $0.044 \mathrm{~J} / \mathrm{s}$ vs. control: $0.121 \mathrm{~J} / \mathrm{s}$ ). Consequently, the $e_{M P A}$ for the patient was considerably lower than that for the control (patient: 0.56 vs. control: 1.06). Further, Lee et al. [15] calculated RV SW for a group of CHD patients and controls, and found that the mean $e_{M P A}$ of the patient group was significantly lower than that of the control group $(0.56 \pm 0.33$ vs.1.56 $\pm 0.85 ; p<0.04)$, despite the fact that the patient group had significantly higher RV SW I (RV SW indexed to body surface area), than the control group $\left(0.205 \pm 0.095 \mathrm{~J} / \mathrm{s} . \mathrm{m}^{2}\right.$ vs. $0.090 \pm 0.038 \mathrm{~J} / \mathrm{s} . \mathrm{m}^{2}$; $p<0.02$ in Figure 4).

\section{Right ventricular-pulmonary vascular function}

The ventricles are coupled with arterial systems to ensure sufficient cardiac output while maximizing the mechanical efficiency [52]. For the right ventricle, the pulmonary vasculature has increased compliance and lower resistance compared with the LV, resulting in lower RV afterload. The RV is well-adjusted to lower afterload with its relatively thinner and more compliant wall [53]. Consequently, RV-PA coupling has a significant impact on RV performance. Thus, pulmonary vasculature characteristics, such as pulmonary arterial stiffness and power loss in the PA, need to be taken into consideration when assessing comprehensive hemodynamic changes in abnormal right heart physiology.

In terms of pulmonary vascular hydraulic power, Milnor et al. [54] used harmonic analysis (a.k.a. Fourier analysis) to calculate pressure energy and kinetic energy components in the pulmonary circulation (Eq. 6):

$$
\dot{W}_{T}=\dot{W}_{M}+\dot{W}_{O}
$$




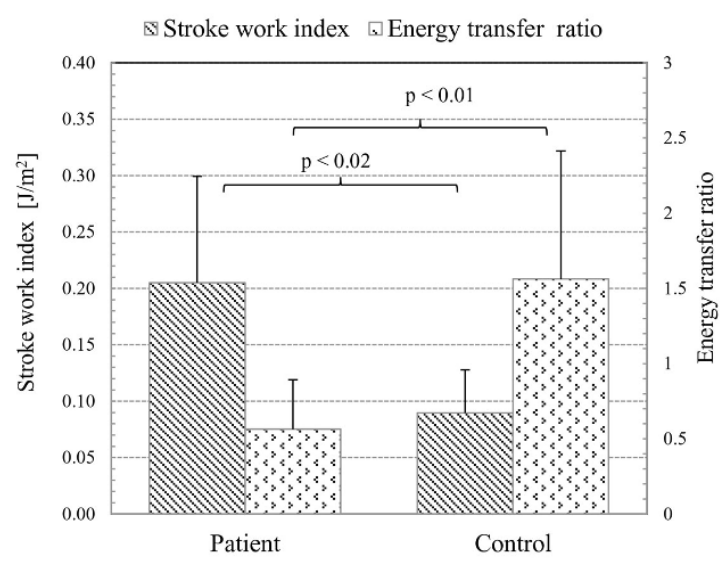

Figure 4 The mean energy transfer ratio $\left(e_{M P A}\right)$ was significantly lower in the CHD patient group $(0.56 \pm 0.33)$ than control group $((1.56 \pm 0.85 ; p<0.04)$. However, the mean RV body surface area indexed SW $\left(S_{1}\right)$ was significantly higher in the CHD patient group $\left(0.205 \pm 0.095 \mathrm{~J} / \mathrm{m}^{2}\right)$ than control group $\left(0.090 \pm 0.038 \mathrm{~J} / \mathrm{m}^{2} ; p<0.02\right)[15]$.

$$
\begin{aligned}
& \dot{W}_{m}=P_{O} Q_{O} \\
& \underset{O}{\dot{W}}=\frac{1}{2} \sum_{n=1}^{N}\left(Q_{n}\right)^{2} Z_{n} \cos \theta_{n}
\end{aligned}
$$

where $\dot{W}_{T}$ is the total hydraulic power computed as the summation of the pressure energy $\left(\dot{W}_{m}\right.$; Eq. $\left.4-2\right)$ associated with mean pressure $\left(P_{O}\right)$ and mean flow $\left(Q_{O}\right)$, and the oscillatory component term ( $\dot{W}_{O}$; Eq. 6-3). Knowing that pressure flow waves can be represented by Fourier series, $N$ (in Eq. 6-3) is the total number of harmonics, $n$ the harmonic number, $Z_{n}$ is PA impedance modulus at the fundamental frequency of pressure wave, and $\theta_{n}$ is impedance phase at that frequency. They showed that $78 \%$ of input power was dissipated through the pulmonary bed. Also, the energy transferred to the PAs for a fixed mean flow decreased as the heart rate increased. Using the same method, Fitzpatrick et al. [55] confirmed the effects of pulmonary vascular obstruction caused by pulmonary thromboembolism on RV afterload.

Hunter et al. [56,57] used Doppler ultrasound and catheterization data of pulmonary arterial hypertension (PAH) patients in a classical mechanical oscillator model [56] and harmonic analysis [57]. They found that the change in pulmonary arterial stiffness calculated from their model correlated with clinical pulmonary arterial stiffness and hemodynamic parameters, such as pulmonary flow, and RV SW. Also, RV-PA coupling studies of PAH have been done in a dog model [48] and an engineered mouse model [50]. Both studies showed that the RV can accommodate the acute increase in RV pressure without increasing RV SW while decreasing the efficiency and arterial compliance, found in PAH patients.

\section{Analytical and computational fluid dynamics methods}

For years, the ventricular pressure-volume relationship (PVR) has provided valuable insight into ventricular contractility and its relationship to different pressure and volume loading conditions. However, invasive catheterization is required for accurate 
pressure measurement. In recent years, therefore, analytical and computer fluid dynamics (CFD) techniques have been used as alternatives to obtain hemodynamics in the ventricles and large arteries, including pulmonary arteries, and aorta.

As mentioned earlier, however, most studies were performed with the left heart disease such as Fontan and aortic stenosis. Ascuitto et al. [58] used an analytical approach for mixing fluids in systematic-to-pulmonary collaterals in Fontan-like circulation. They evaluated the pulmonary arterial pressure and increase of flow energy loss due to mixing in collateral flows. Dasi et al. [59] formulated energy dissipation in the total cavopulmonary connection (TCPC) using dimensionless analysis by applying analytical approach and found that it can determine the hemodynamic characteristics, such as energy dissipation, cardiac output change, and flow split in TCPC. Also, they used the generalized theoretical analysis for energy dissipation and introduced new energy indices, such as circulation energy dissipation index (CEDI), aortic valve energy dissipation index (AV-EDI), and total TCPC energy dissipation index (TCPC-EDI), to evaluate complex hemodynamics in patients (Eq. 7; [60]).

$$
\begin{aligned}
& \text { Circulation energy dissipation index }(\mathrm{CEDI})=\frac{\text { Mean } S W}{\left(\rho \frac{Q^{3}}{B S A^{2}}\right)} \quad(7-1) \\
& \text { Aortic valve energy dissipation index }(\mathrm{AV}-\mathrm{EDI})=\left(\frac{B S A}{A_{A}}\right)^{2}\left(\frac{1}{S}-1\right)^{2} \quad(7-2) \\
& \text { Total TCPC energy dissipation index (TCPC - EDI) }=\frac{\varepsilon}{\rho \frac{Q^{3}}{B S A^{2}}} \quad(7-3)
\end{aligned}
$$

where $\rho$ is blood density, $Q$ : mean flow rate, $A_{A}$ is aortic cross-sectional area, $S$ is geometrical shape factor, and $\varepsilon\left(=5.33 \times 10^{-5} \frac{Q^{3}}{A_{A}^{2}}\left[\frac{1}{S}-1\right]^{2}\right)$ is mean energy dissipation at TCPC. CEDI represents the level of energy dissipation in normal physiology, while the other two indices, AV-EDI and TCPC-EDI, illustrated energy dissipation in abnormal physiology linked to aortic valve insufficiency and Fontan physiology, respectively.

Meanwhile, Hunter et al. [61] used biplane X-ray angiograms for reconstruction of 3D patient-specific PA geometry, which was adopted for CFD analysis (Figure 5). They showed the details of the changes in PA hemodynamics for PAH patients with pre/post-operative septal defect and reactivity challenge. Both cases showed that PA hemodynamics, such as pressure, flow, wall shear stress, and vascular stiffness, were normalized after repair. Tang et al. [62] used a multiphysics-based fluid-structure interaction analysis, incorporating myocardial tissue characteristics. They confirmed the favourable changes in RV hemodynamics after a surgical procedure; thus improving RV EF (Figure 6). Also, Das et al. [49] computed energy transfer rate $\left(e_{M P A}\right)$ at the PAs (as described earlier) using CFD to obtain energy transfer ratio between the RV and MPA.

Many recent studies have investigated the Fontan physiology that involves the total cavopulmonary connection (TCPC) between the venae cava and the PA while bypassing the RV. Soerensen et al. [63] performed CFD analysis together with 2D phase contrast 

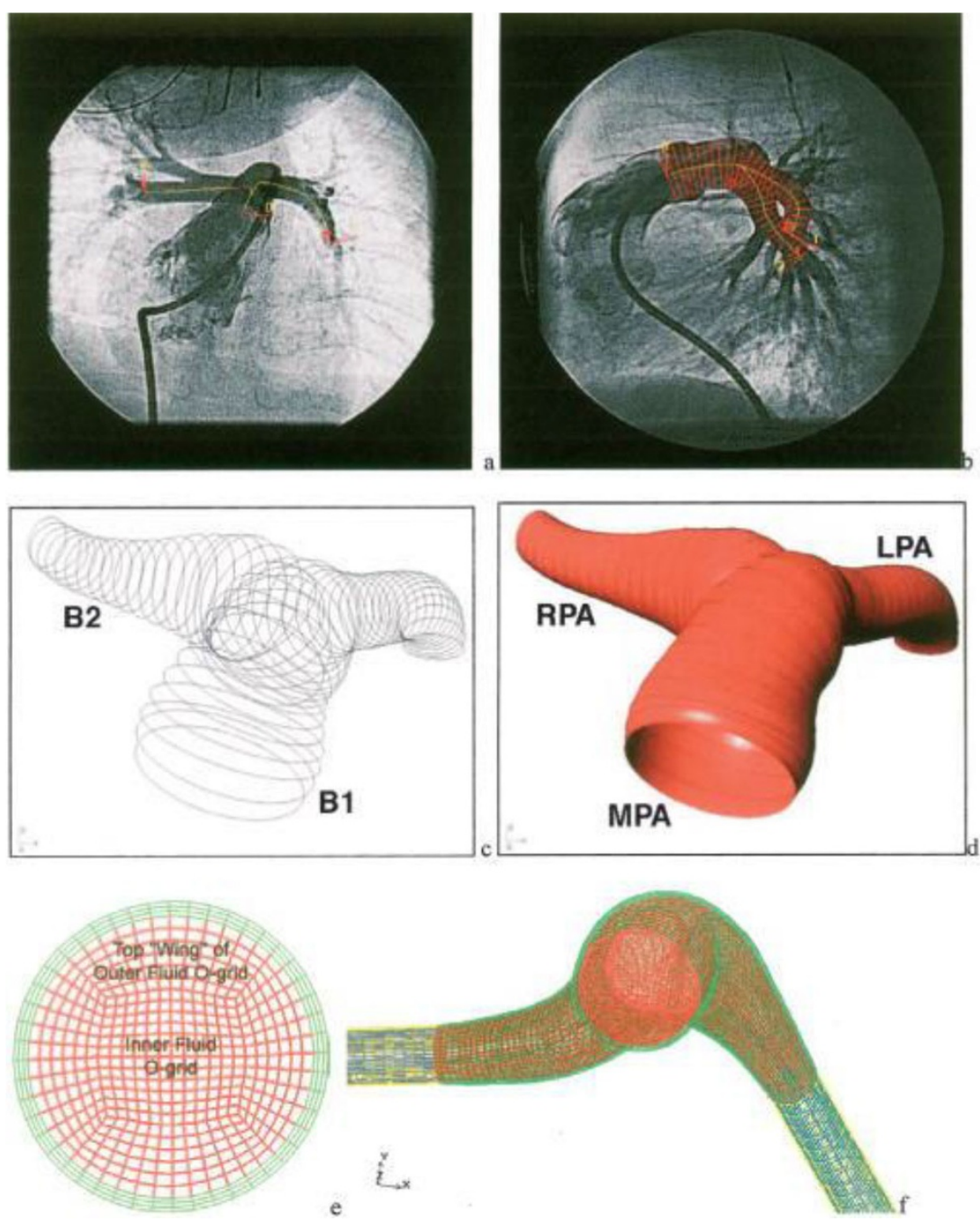

Figure 5 Patient-specific 3D geometry reconstruction and mesh generation procedures using $\mathrm{X}$-ray angiogram. A) AP images of PA and B) lateral PA bi-plane angiogram showing centerlines overlapped on the AP image and diameter superimposed on the later image. C) the skeleton image of the PA, D) after creating surfaces on the skeleton image. E) The fluid domains (in red) and structure domains (in green) are shown, and F) a representative cross section of the MPA mesh [61].

MRI to obtain flow and power loss in a TCPC configuration. They calculated power loss in a complex TCPC using both CFD analysis and MRI measurement (Eq. 8):

$$
\dot{E}_{T C P C}=\dot{E}_{S V C}+\dot{E}_{I V C}-\dot{E}_{L P A}-\dot{E}_{R P A}
$$

where $\dot{E}_{S V C}$ is the rate of energy transfer at the superior vena cava (SVC), $\dot{E}_{I V C}$ is the rate of energy transfer at the inferior vena cava (IVC), $\dot{E}_{L P A}$ is the rate of energy transfer at the left PA (LPA), and $\dot{E}_{R P A}$ is the rate of energy transfer at the right PA (RPA). In line with the research conducted by Soerensen et al., Whitehead et al. [64] reported that the non-linear power loss through TCPC connection significantly increased during exercise in Fontan patients (Figure 7). In general, these methodologies for assessing energy or power loss in Fontan circulation can be applied to the right heart disease, especially in the case of RV-PC dysfunction. 


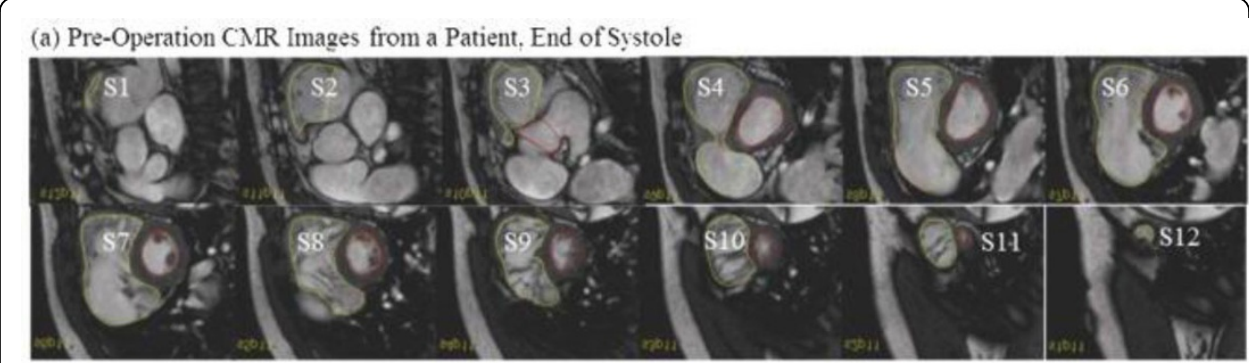

(b) Segmented Contours of RV-LV for Model Construction
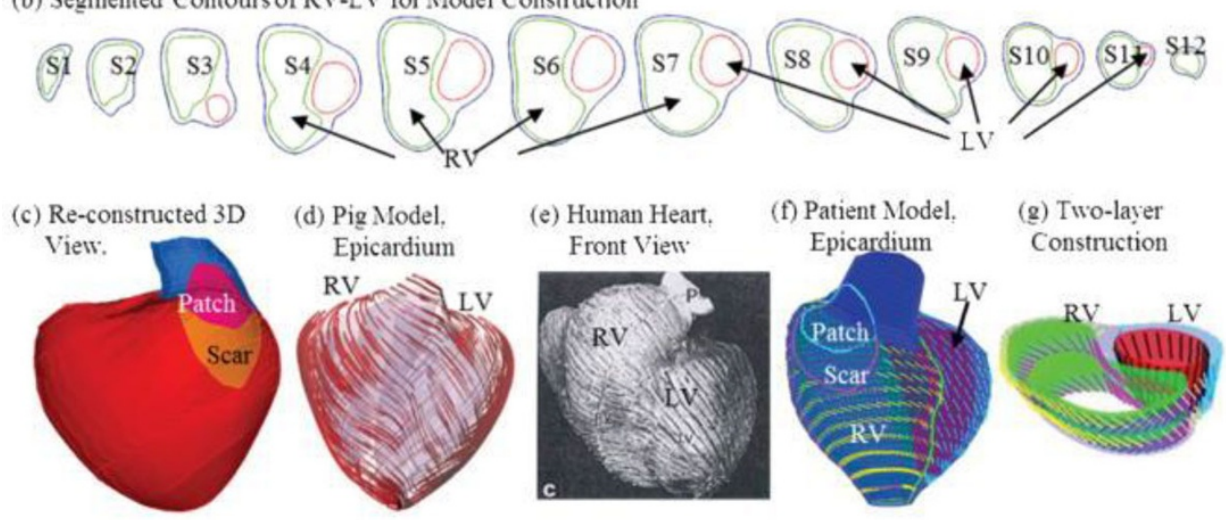

Figure 6 A model construction procedures using cardiac MR imaging for CFD: a) cardiac MR images for a subject, b) contouring for the ventricles, c) reconstructed 3D chambers, d) a pig model showing myocardial fiber orientation, e) a human heart with fiber orientation, f) CFD model incorporating myocardial fiber orientation, and 3) two-layer model [62]

\section{Emerging techniques: 4D phase contrast MRI}

4D phase contrast MRI, three dimensional and directional velocity data over the cardiac cycle, can be performed for ventricular chambers and large vessels [65-67]. This technique enables us to visualize and quantify time varying 3D blood flow in CHD patients (Figure 8) in contrast to standard 2D phase contrast MRI acquisitions of most clinical MR protocols.

Considering the complex nature of 3D blood flow in CHD patients, the irregularity and fluctuation of flow characteristics are important aspects of energy-based analysis [67-69]. 4D phase contrast MRI is being increasingly used not only as a tool for the complex blood flow visualization, but also for calculating hemodynamics and energy endpoints. For instance, the kinetic energy (KE) of blood flow can be calculated using 3D velocity fields obtained from 4D phase contrast MRI data [70-73]. Carlsson et al. [70] quantified the ventricular KE in normal healthy subjects. They calculated KE using a simple equation (Eq. 9):

$$
\mathrm{KE}=\sum_{n=1}^{N_{\text {vox }}}\left(\frac{1}{2} \times \rho \times u_{i}^{2}\right)
$$

where $N_{\text {vox }}$ is total number of voxels in the ventricle, $\rho$ is the density of a voxel which is assumed to be $1.05 \mathrm{~g} / \mathrm{ml}$, and $u$ is the blood velocity in the voxel. They found that the average KE in both the ventricles was related to EDV, ESV, and SV. The computed KE for the LV and RV accounted for less than 1\% and 3\% of the external work done by the LV and RV at rest, respectively. However, it increased up to $3 \%$ and $24 \%$ for the LV and RV during peak exercise. 


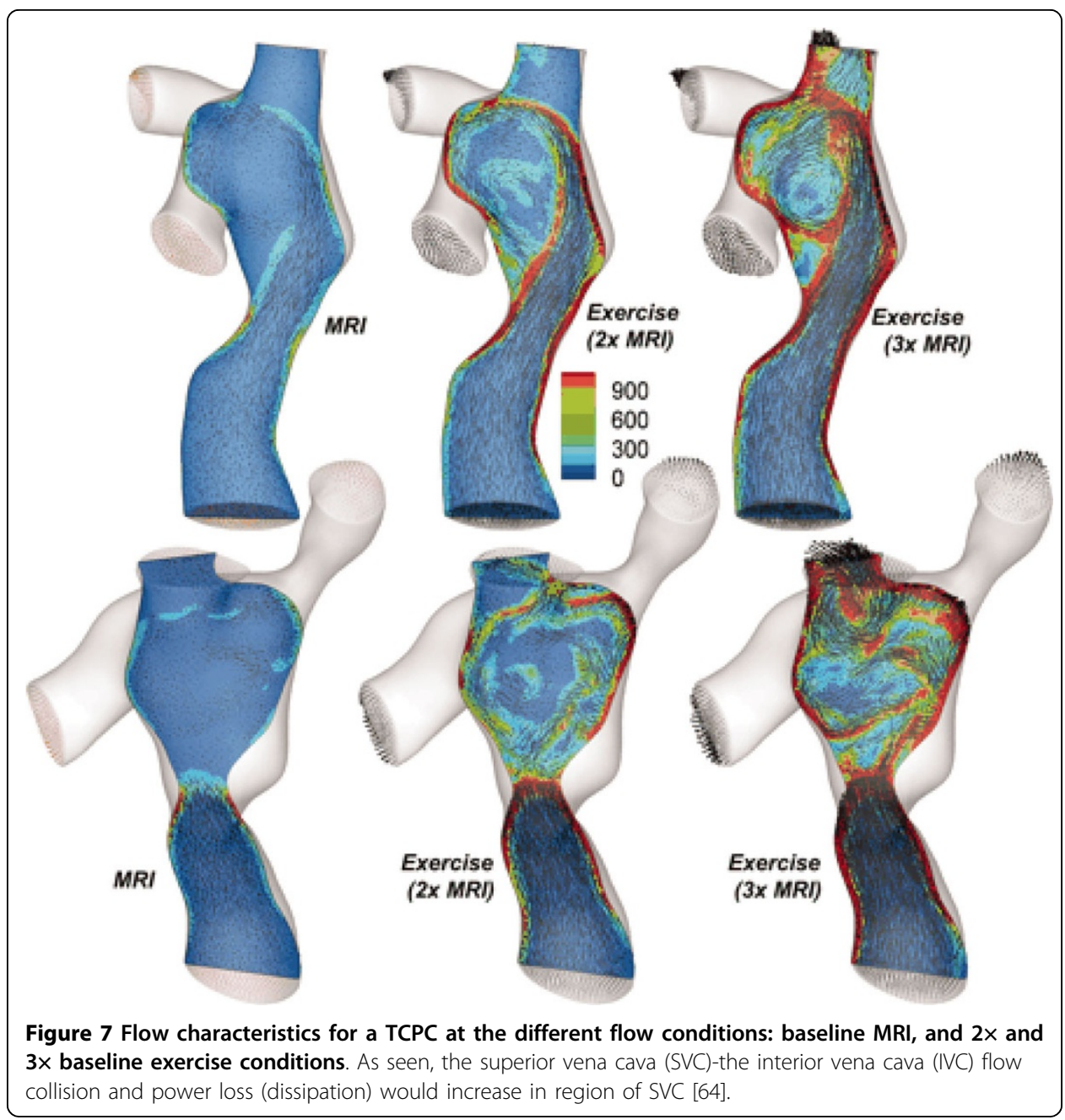

Dyverfeldt et al. $[68,69]$ demonstrated the relation between the standard deviation of the blood flow velocity and turbulent intensity computed from 4D phase contrast MRI, which allowed them to compute turbulent kinetic energy (TKE).

$$
\mathrm{TKE}=\sum_{n=1}^{N_{v o x}}\left(\frac{1}{2} \times \rho \times u_{n}^{\prime 2}\right)
$$

where $u^{\prime}\left(=\sqrt{\frac{1}{N} \sum_{i=1}^{N}\left(u_{i}-\bar{u}\right)^{2}}\right)$ is the fluctuating component in velocity $(\mathrm{u})$. In follow-up study, they showed that the total TKE in the ascending aorta in patients with aortic stenosis and dilation was related to pressure loss [71]. Lantz et al. [73] showed an agreement between KE and TKE computed from two methodologies, 4D phase contrast MRI and CFD. They indicated that KE decreased at the stenosis after the repair, while the total TKE levels decreased in the coarctation although blood flow increased after the repair (Figure 9).

Further, Lee et al. [74,75] used 4D phase contrast MRI data (Figure 10) to compute a hemodynamic endpoint, energy loss in the branch PAs, non-invasively to characterize RV-PC dysfunction in CHD patients. The used blood flow and pressure drop in the branch PAs obtained from 4D phase contrast MRI. Energy loss in the branch PAs was 


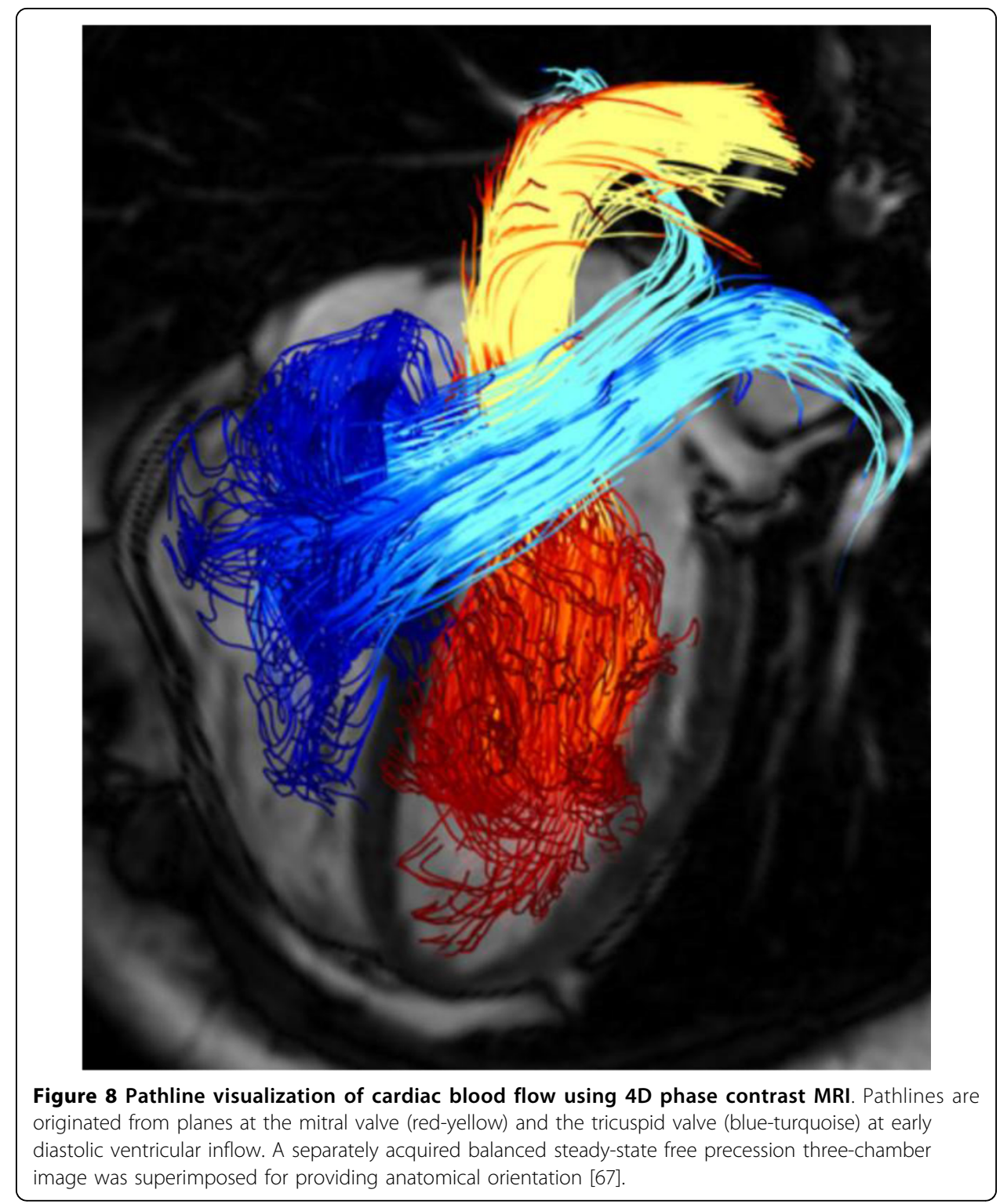

defined as the difference in energy transfer between inlet (MPA) and outlets (the branch PAs, i.e., LPA and RPA) as shown in Eq. 11.

$$
\dot{E}_{L O S S P A}=\dot{E}_{M P A}-\dot{E}_{L P A}-\dot{E}_{R P A}
$$

They showed that the total energy loss in the branch PAs for the patients with PA pathophysiology was an order of magnitude larger than the control subjects. More importantly, the total energy loss varied significantly among patients who had the different levels of RV-PC dysfunction (Figure 11 and 12). It can be noted that energy loss endpoint may be a sensitive measure in assessing the level of RV-PC dysfunction for CHD patients.

\section{Limitation}

Although 4D phase contrast MRI is a validated technique to measure blood velocity, it has limitations including 1) relatively long scan time (10 20 minutes depending on the acquisition volume), 2) moderate spatial resolution $\left(2.0 \sim 2.5 \mathrm{~mm}^{3}\right)$ which limits its 


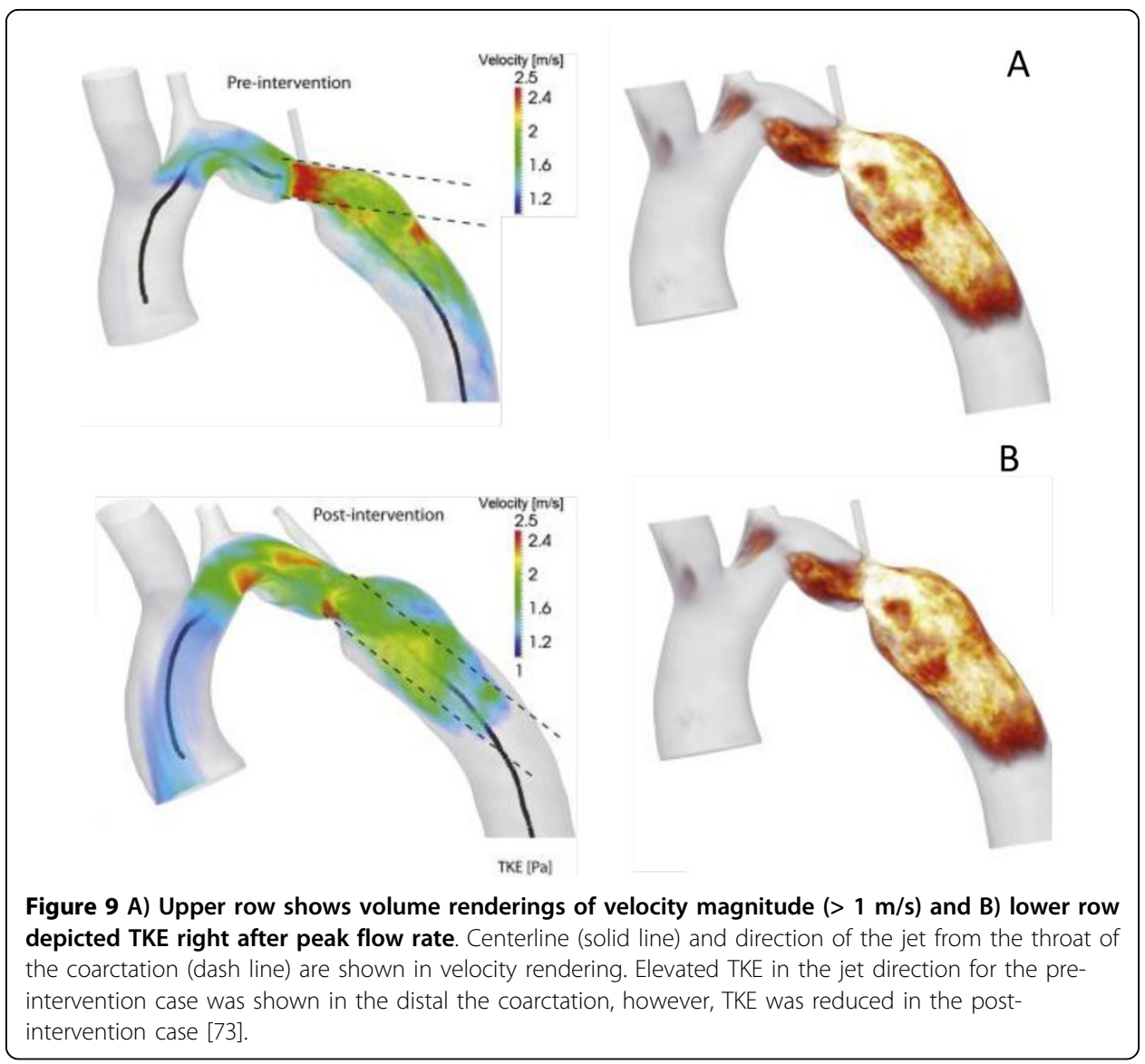

applicability to compute hemodynamics near or at the vessel wall, and 3) requirement for complex data post-processing. New approaches are being developed to address many of these problems. For example, fast imaging techniques, such as k-space undersampling (radial acquisition, compress sensing, and etc) [76,77] and multidimensional parallel imaging [78,79], have been proposed to reduce the scan time (down to 5 8 minutes) and to improve spatiotemporal resolution. In terms of computing hemodynamics near or at wall using 4D phase contrast MRI, Stalder et al. [80] proposed a method that combines B-spline interpolation and Green's theorem to optimize

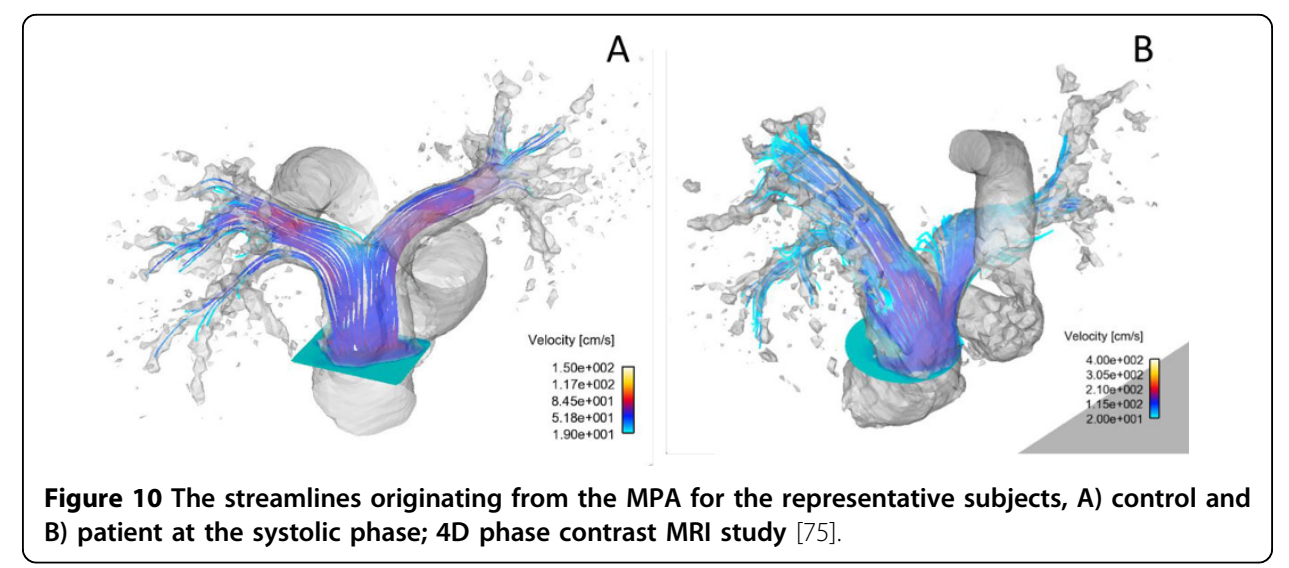



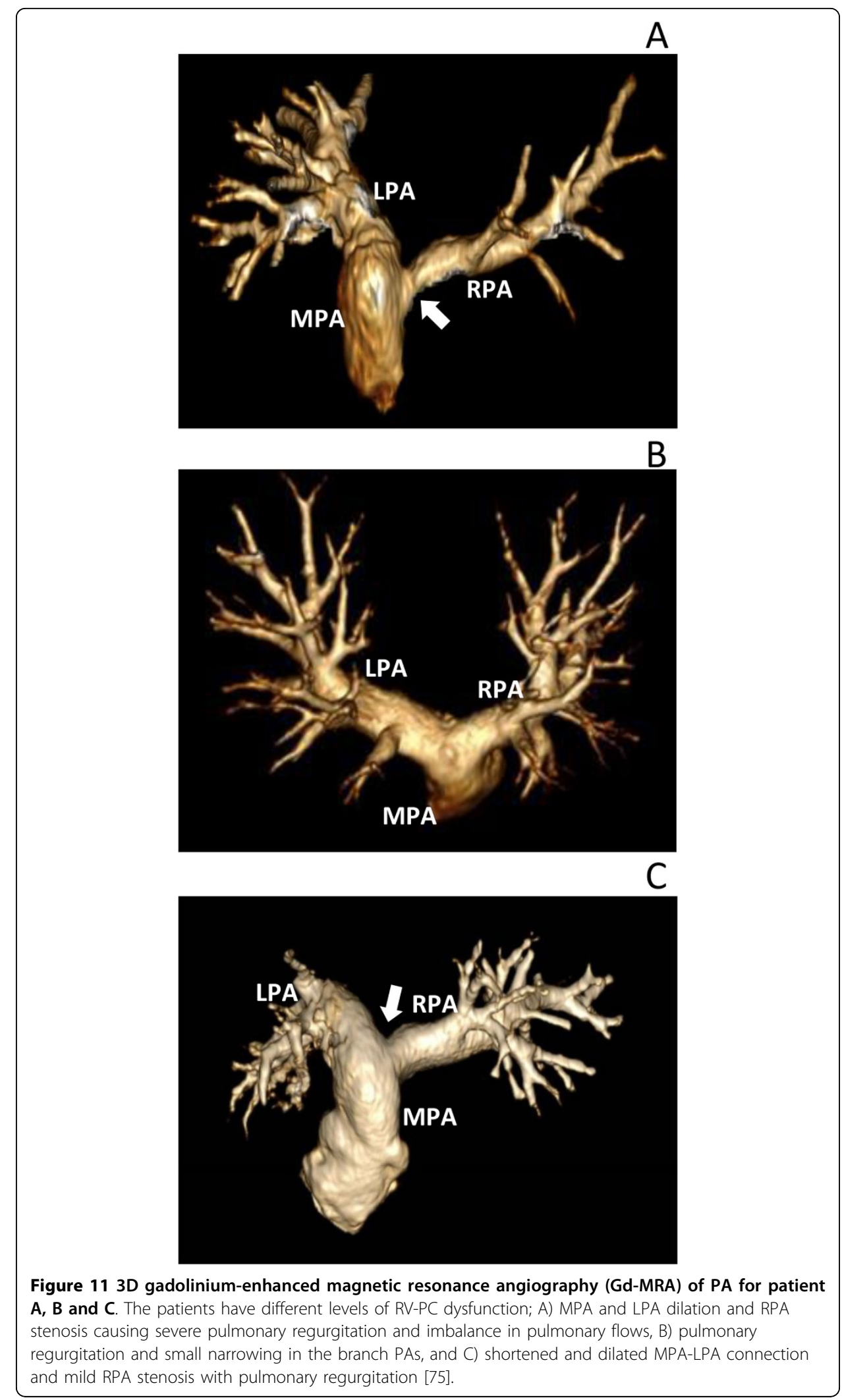

B 

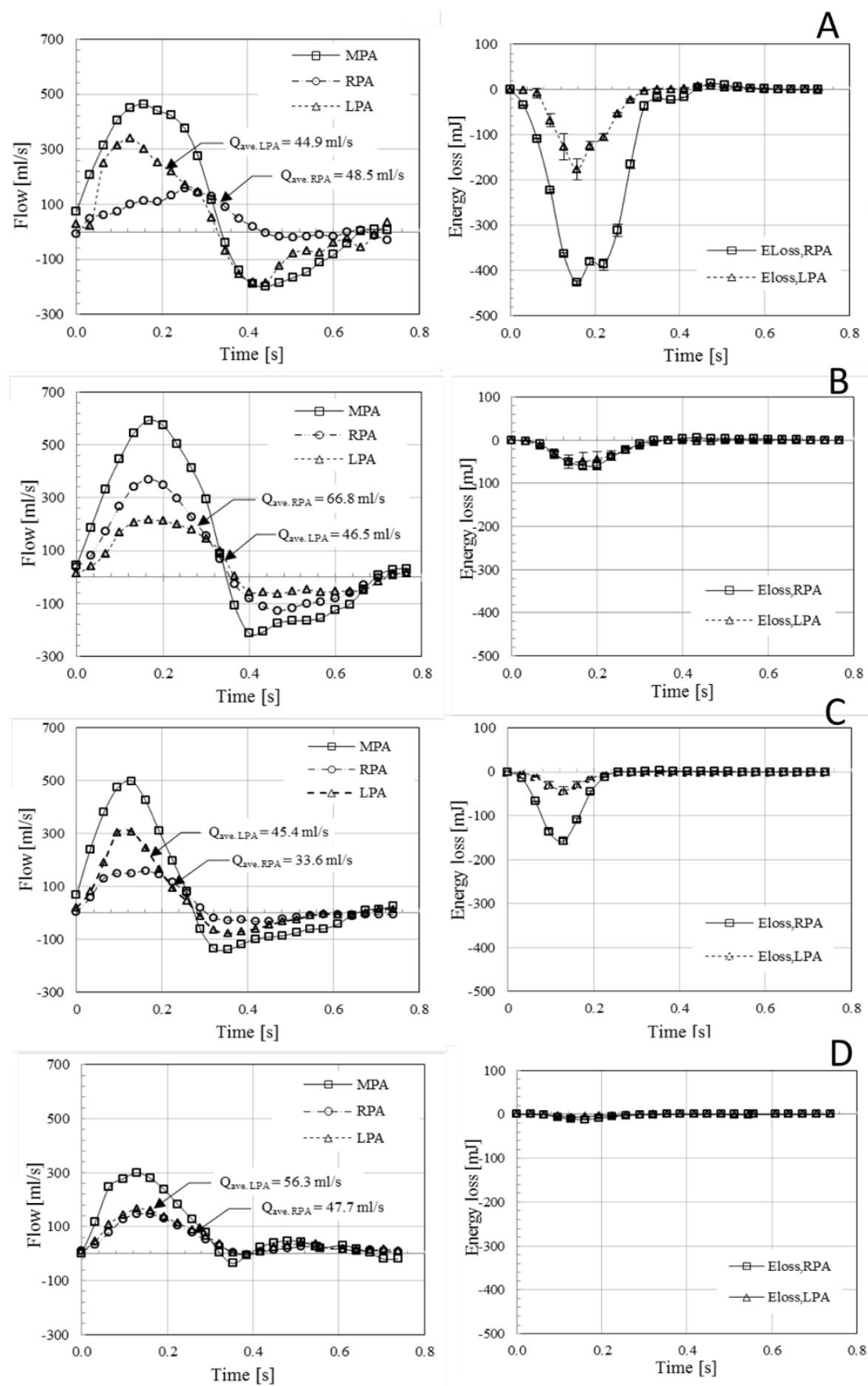

Figure 12 The characteristics of blood flow (left column) and energy loss in the branch PAs (right column) for three patients (A-C) and a control subject (D) [75]

quantification of blood flow and wall shear stress. Further, several groups have developed methodologies for fast and accurate data post-processing [81-84]. Together with continuous improvements in MR sequences, MR hardware and software, and computing power, the 4D phase contrast MRI has drawn increased attention from researchers and clinicians. The 4D phase contrast MRI can make a positive impact on current cardiac MRI protocols, leading to better diagnosis of patho-physiologic vasculature. 


\section{Future direction}

The computation of energy-based endpoints, such as ventricular pressure-volume relationships, stroke work, and efficiency, traditionally requires cardiac catheterization. Computation fluid dynamics (CFD) utilizing data from ultrasound or phase contrast MRI (and pressure data from catheterization) can be used to estimate energy-based endpoints. Recently, non-invasive 4D phase contrast MRI has become available to compute energy-based endpoints avoiding catheterization, and consequently reducing risks for patients while decreasing costs. Therefore, we believe that non-invasive methodologies, such as 4D phase contrast MRI, can be used to calculate energy-based endpoints to follow longitudinally CHD patients and help with interventional planning.

\section{Conclusions}

The RV-PC dysfunction is a common chronic disease in post-operative CHD patients that poses a threat to the patient's lives over time unless it is timely treated. The status of RV-PC dysfunction needs a careful evaluation during routine follow-up for a patient because of its adverse effect on RV-PA hemodynamics. The RV pressure-volume relationship (PVR) is the gold standard for detailed ventricular function throughout the cardiac cycle independent of loading conditions. Energy-based endpoints derived from PVR, such as RV SW, the ventricular efficiency, and energy transfer ratio between the RV and the MPA, have also been useful means to characterize the RV performance. However, these approaches are not widely applicable in clinical settings since they require invasive catheterization and involve simultaneously measured RV pressure and volume. Therefore, the new energy endpoints, for instance, energy dissipation, energy loss in the PAs, kinetic energy loss, or turbulence kinetic energy, computed using non-invasive methodologies, 4D phase contrast MRI and CFD, are emerging, and may be useful surrogates. As described in this review, energy-based endpoints are capable of better delineating and quantifying comprehensive hemodynamics and associated energy changes caused by RV-PC dysfunction. Therefore, energy-based endpoints can be useful measures in helping clinicians to make better clinical decisions for patients with abnormal RV-PA physiology.

\footnotetext{
List of abbreviations

CHD: congenital heart disease; RV: right ventricle; EF: ejection fraction; ESP: end-systolic pressure; RV-PC: RV-PA circulation; EDV: end-diastolic volume; PA: pulmonary artery; PVR: pressure-volume relationship; SW: stroke work; $E_{\text {es }}$ : ventricular end-systolic elastance; CFD: computational fluid dynamics; MRI: magnetic resonance imaging; EDV: enddiasystolic volume; ESV: end-systolic volume; EDV: EDV indexed by body surface area; LV: left ventricle; SV: stroke volume; $\mathrm{MVO}_{2}$ : myocardial oxygen consumption; PET: positron emission tomography; MAP: mean arterial pressure; $A_{m}$ : MPA area; $E_{\text {net }}$ : net energy transfer at the MPA; T: cardiac cycle; $\dot{W}_{T}$ : the total hydraulic power; $\dot{W}_{m}$ : the summation of the pressure energy; $P_{O}$ : mean pressure; $Q_{O}$ : mean flow; $\dot{W}_{O}$ : oscillatory pressure energy; $N$ : the total number of harmonics; $n$ : harmonic number; $Z_{n}$ : PA impedance modulus at the funda-mental frequency of pressure wave; $\theta_{n}$ : impedance phase at that frequency; PAH: pulmonary arterial hypertension; TCPC: the total cavopulmonary connection; CEDI: circulation energy dissipation index; AV-EDI: aortic valve energy dissipation index; TCPC-EDI: total TCPC energy dissipation index; $\rho$ : the density of a blood $\left(=1,050 \mathrm{~kg} / \mathrm{m}^{3}\right) ; A_{A}$ : aortic cross-sectional area; $S$ : geometrical shape fact; HR: heart rate; LVM: left ventricular mass; $e_{M P A}$ : energy transfer ratio at the MPA; $P$ : RV pressure; $V:$ RV volume; $\dot{E}$ : Energy transfer rate; MPA: main PA; LPA: left PA; RPA: right PA; $p_{m}$ : MPA pressure; $\vec{u}_{m}$ : velocity at the MPA; $\varepsilon$ : the mean energy dissipation at TCPC; $\dot{E}_{T C P C}$ : the rate of energy loss through TCPC; $\dot{E}_{S V C}$ : the rate of energy loss at the superior vena cava; $\dot{E}_{I V C}$ : the rate of energy loss at the inferior vena cava; KE: kinetic energy; $N_{\text {vox }}$ : total number of voxels in the ventricle; U: the blood velocity; TKE: turbulent kinetic energy; $u^{\prime}$ : fluctuating component in velocity; $\dot{E}_{L O S S P A}$ : Energy loss in the branch PAs;
}

Competing interests

The authors declare that they have no competing interests. 


\section{Declarations}

Publication of this article was paid with funding from Cincinnati Children's Hospital Medical Center.

This article has been published as part of BioMedical Engineering OnLine Volume 14 Supplement 1, 2015:

Cardiovascular Disease and Vulnerable Plaque Biomechanics. The full contents of the supplement are available online at http://www.biomedical-engineering-online.com/supplements/14/S1

\section{Authors' details}

${ }^{1}$ The Heart Institute, Cincinnati Children's Hospital Medical Center, 3333 Burnet Avenue, Cincinnati, OH, 45229, USA.

${ }^{2}$ The Department of Mechanical and Materials Engineering, University of Cincinnati, OH, 45221, USA.

Published: 9 January 2015

\section{References}

1. Go AS, Mozaffarian D, Roger VL, Benjamin EJ, Berry JD, Blaha MJ, Dai S, Ford ES, Fox CS, Franco S, et al: Heart disease and stroke statistics-2014 update: a report from the American Heart Association. Circulation 2014, 129:e28-e292.

2. Hoffman Jl, Kaplan S, Liberthson RR: Prevalence of congenital heart disease. Am Heart J 2004, 147:425-439.

3. Ooi A, Moorjani N, Baliulis G, Keeton BR, Salmon AP, Monro JL, Haw MP: Medium term outcome for infant repair in tetralogy of Fallot: Indicators for timing of surgery. Eur J Cardiothorac Surg 2006, 30:917-922.

4. Owen AR, Gatzoulis MA: Tetralogy of Fallot: Late outcome after repair and surgical implications. Semin Thorac Cardiovasc Surg Pediatr Card Surg Annu 2000, 3:216-226.

5. Khairy P, Landzberg MJ, Gatzoulis MA, Lucron H, Lambert J, Marcon F, Alexander ME, Walsh EP: Value of programmed ventricular stimulation after tetralogy of fallot repair: a multicenter study. Circulation 2004, 109:1994-2000.

6. Davlouros PA, Niwa K, Webb G, Gatzoulis MA: The right ventricle in congenital heart disease. Heart 2006, 92(Suppl 1):i27-38.

7. d'Udekem Y, Ovaert C, Grandjean F, Gerin V, Cailteux M, Shango-Lody P, Vliers A, Sluysmans T, Robert A, Rubay J: Tetralogy of Fallot: transannular and right ventricular patching equally affect late functional status. Circulation 2000, 102:I1116-122.

8. Harrild DM, Berul Cl, Cecchin F, Geva T, Gauvreau K, Pigula F, Walsh EP: Pulmonary valve replacement in tetralogy of Fallot: impact on survival and ventricular tachycardia. Circulation 2009, 119:445-451.

9. Hazekamp MG, Kurvers MM, Schoof PH, Vliegen HW, Mulder BM, Roest AA, Ottenkamp J, Dion RA: Pulmonary valve insertion late after repair of Fallot's tetralogy. Eur J Cardiothorac Surg 2001, 19:667-670.

10. Miyazaki A, Yamamoto M, Sakaguchi H, Tsukano S, Kagisaki K, Suyama K, Ohuchi H, Kurosaki K, Yagihara T, Yamada O: Pulmonary valve replacement in adult patients with a severely dilated right ventricle and refractory arrhythmias after repair of tetralogy of fallot. Circ J 2009, 73:2135-2142.

11. Therrien J, Provost Y, Merchant N, Williams W, Colman J, Webb G: Optimal timing for pulmonary valve replacement in adults after tetralogy of Fallot repair. Am J Cardiol 2005, 95:779-782.

12. Murphy JG, Gersh BJ, Mair DD, Fuster V, McGoon MD, Ilstrup DM, McGoon DC, Kirklin JW, Danielson GK: Long-term outcome in patients undergoing surgical repair of tetralogy of Fallot. N Engl I Med 1993, 329:593-599.

13. Pigula FA, Khalil PN, Mayer JE, del Nido PJ, Jonas RA: Repair of tetralogy of Fallot in neonates and young infants. Circulation 1999, 100:II157-161.

14. Lee N DA, Gottliebson W, Banerjee RK: Comparison of stroke work between repaired tetralogy of Fallot and normal right ventricular physiologies. Heart Vessels 2011, DOI 10.1007/s00380-011-0212-7.

15. Lee NDA, Taylor M, Hor K, Banerjee RK: Energy Transfer Ratio as a Metric of Right Ventricular Efficiency in Repaired Congenital Heart Disease. Congenital Heart Disease 2012, DOI: 10.1111/chd.12034.

16. Bove EL, Kavey RE, Byrum CJ, Sondheimer HM, Blackman MS, Thomas FD: Improved right ventricular function following late pulmonary valve replacement for residual pulmonary insufficiency or stenosis. J Thorac Cardiovasc Surg 1985, 90:50-55.

17. Gutgesell HP: Pulmonary valve insufficiency: malignant or benign? J Am Coll Cardiol 1992, 20:174-175.

18. Kadner A, Bauersfeld U, Pretre R, Valsangiacomo-Buechel ER, Dodge-Khatami A: Chronic pulmonary valve insufficiency after repaired tetralogy of Fallot: diagnostics, reoperations and reconstruction possibilities. Expert Rev Cardiovasc Ther 2007, 5:221-230.

19. Burkhoff D, Mirsky I, Suga H: Assessment of systolic and diastolic ventricular properties via pressure-volume analysis: a guide for clinical, translational, and basic researchers. Am J Physiol Heart Circ Physiol 2005, 289:H501-512

20. Therrien J, Siu SC, McLaughlin PR, Liu PP, Williams WG, Webb GD: Pulmonary valve replacement in adults late after repair of tetralogy of fallot: are we operating too late? J Am Coll Cardiol 2000, 36:1670-1675.

21. Riesenkampff E, Mengelkamp L, Mueller M, Kropf S, Abdul-Khaliq H, Sarikouch S, Beerbaum P, Hetzer R, Steendijk P, Berger F, et al: Integrated analysis of atrioventricular interactions in tetralogy of Fallot. Am J Physiol Heart Circ Physiol 2010, 299:H364-371.

22. Richmond ME, Cabreriza SE, Van Batavia JP, Quinn TA, Kanter JP, Weinberg AD, Mosca RS, Quaegebeur JM, Spotnitz HM: Direction of preoperative ventricular shunting affects ventricular mechanics after Tetralogy of Fallot repair. Circulation 2008, 118:2338-2344.

23. Uebing A, Fischer G, Schmiel F, Onnasch DG, Scheewe J, Kramer HH: Angiocardiographic pressure volume loops in the analysis of right ventricular function after repair of tetralogy of Fallot. Int J Cardiovasc Imaging 2005, 21:469-480.

24. Therrien J, Siu SC, Harris L, Dore A, Niwa K, Janousek J, Williams WG, Webb G, Gatzoulis MA: Impact of pulmonary valve replacement on arrhythmia propensity late after repair of tetralogy of Fallot. Circulation 2001, 103:2489-2494.

25. Cheung EW, Lam WW, Cheung SC, Cheung YF: Functional implications of the right ventricular myocardial performance index in patients after surgical repair of tetralogy of Fallot. Heart Vessels 2008, 23:112-117.

26. Pohost GM, Hung L, Doyle M: Clinical use of cardiovascular magnetic resonance. Circulation 2003, 108:647-653.

27. Pavlicek M, Wahl A, Rutz T, de Marchi SF, Hille R, Wustmann K, Steck H, Eigenmann C, Schwerzmann M, Seiler C: Right ventricular systolic function assessment: rank of echocardiographic methods vs. cardiac magnetic resonance imaging. Eur J Echocardiogr 2011, 12:871-880. 
28. Warnes CA, Williams RG, Bashore TM, Child JS, Connolly HM, Dearani JA, Del Nido P, Fasules JW, Graham TP, Hijazi ZM, et al: ACC/AHA 2008 Guidelines for the Management of Adults with Congenital Heart Disease: Executive Summary. Circulation 2008, 118:2395-2451.

29. Khambadkone S, Coats L, Taylor A, Boudjemline Y, Derrick G, Tsang V, Cooper J, Muthurangu V, Hegde SR, Razavi RS, et al: Percutaneous pulmonary valve implantation in humans: results in 59 consecutive patients. Circulation 2005, 112:1189-1197.

30. Momenah TS, El Oakley R, Al Najashi K, Khoshhal S, Al Qethamy H, Bonhoeffer P: Extended application of percutaneous pulmonary valve implantation. J Am Coll Cardiol 2009, 53:1859-1863.

31. Frank O: The basic shape of the arterial pulse. First treatise: Mathematical analysis. Journal of Molecular and Cellular Cardiology 1990, 22:255-277

32. Knowlton FP, Starling EH: The influence of variations in temperature and blood-pressure on the performance of the isolated mammalian heart. J Physiol 1912, 44:206-219.

33. Patterson SW, Piper H, Starling EH: The regulation of the heart beat. J Physio/ 1914, 48:465-513.

34. Bing RJ, Hammond MM, et al: The measurement of coronary blood flow, oxygen consumption, and efficiency of the left ventricle in man. Am Heart J 1949, 38:1-24.

35. Gibbs CL: Cardiac energetics. Physiol Rev 1978, 58:174-254

36. Sagawa K: The ventricular pressure-volume diagram revisited. Circ Res 1978, 43:677-687.

37. Suga $\mathrm{H}$ : Time course of left ventricular pressure-volume relationship under various enddiastolic volume. Jpn Heart $J$ 1969, 10:509-515.

38. Suga H: Ventricular energetics. Physiol Rev 1990, 70:247-277.

39. Suga $\mathrm{H}$, Sagawa K: Instantaneous pressure-volume relationships and their ratio in the excised, supported canine left ventricle. Circ Res 1974, 35:117-126.

40. McKay RG, Aroesty JM, Heller GV, Royal H, Parker JA, Silverman KJ, Kolodny GM, Grossman W: Left ventricular pressurevolume diagrams and end-systolic pressure-volume relations in human beings. J Am Coll Cardiol 1984, 3:301-312.

41. Suga H: Total mechanical energy of a ventricle model and cardiac oxygen consumption. Am J Physiol 1979, 236 H498-505.

42. Suga H, Sagawa K, Shoukas AA: Load independence of the instantaneous pressure-volume ratio of the canine left ventricle and effects of epinephrine and heart rate on the ratio. Circ Res 1973, 32:314-322.

43. Mason SJ, Fortuin NJ: The use of echocardiography for quantitative evaluation of left ventricular function. Prog Cardiovasc Dis 1978, 21:119-132.

44. Fortuin NJ, Pawsey CG: The evaluation of left ventricular function by echocardiography. Am J Med 1977, 63:1-9.

45. Baxley WA, Dodge HT, Rackley CE, Sandler H, Pugh D: Left ventricular mechanical efficiency in man with heart disease. Circulation 1977, 55:564-568.

46. De Tombe PP, Jones S, Burkhoff D, Hunter WC, Kass DA: Ventricular stroke work and efficiency both remain nearly optimal despite altered vascular loading. Am J Physiol 1993, 264:H1817-1824.

47. Porenta G, Cherry S, Czernin J, Brunken R, Kuhle W, Hashimoto T, Schelbert HR: Noninvasive determination of myocardial blood flow, oxygen consumption and efficiency in normal humans by carbon-11 acetate positron emission tomography imaging. Eur J Nucl Med 1999, 26:1465-1474.

48. Bellofiore A, Roldan-Alzate A, Besse M, Kellihan HB, Consigny DW, Francois CJ, Chesler NC: Impact of acute pulmonary embolization on arterial stiffening and right ventricular function in dogs. Ann Biomed Eng 2013, 41:195-204.

49. Das A, Banerjee RK, Gottliebson WM: Right ventricular inefficiency in repaired tetralogy of fallot: proof of concept for energy calculations from cardiac MRI data. Ann Biomed Eng 2010, 38:3674-3687.

50. Wang Z, Schreier DA, Hacker TA, Chesler NC: Progressive right ventricular functional and structural changes in a mouse model of pulmonary arterial hypertension. Physiological reports 2013, 1:e00184.

51. Ho SY, Nihoyannopoulos P: Anatomy, echocardiography, and normal right ventricular dimensions. Heart 2006, 92(Suppl 1):i2-13.

52. Sunagawa K, Maughan WL, Burkhoff D, Sagawa K: Left ventricular interaction with arterial load studied in isolated canine ventricle. Am J Physiol 1983, 245:H773-780.

53. Voelkel NF, Quaife RA, Leinwand LA, Barst RJ, McGoon MD, Meldrum DR, Dupuis J, Long CS, Rubin LJ, Smart FW, et al: Right ventricular function and failure: report of a National Heart, Lung, and Blood Institute working group on cellular and molecular mechanisms of right heart failure. Circulation 2006, 114:1883-1891.

54. Milnor WR, Bergel DH, Bargainer JD: Hydraulic power associated with pulmonary blood flow and its relation to heart rate. Circ Res 1966, 19:467-480.

55. Fitzpatrick JM, Grant BJ: Effects of pulmonary vascular obstruction on right ventricular afterload. Am Rev Respir Dis 1990, 141:944-952.

56. Hunter KS, Gross JK, Lanning CJ, Kirby KS, Dyer KL, Ivy DD, Shandas R: Noninvasive methods for determining pulmonary vascular function in children with pulmonary arterial hypertension: application of a mechanical oscillator model. Congenit Heart Dis 2008, 3:106-116.

57. Hunter KS, Lee PF, Lanning CJ, Ivy DD, Kirby KS, Claussen LR, Chan KC, Shandas R: Pulmonary vascular input impedance is a combined measure of pulmonary vascular resistance and stiffness and predicts clinical outcomes better than pulmonary vascular resistance alone in pediatric patients with pulmonary hypertension. Am Heart $J$ 2008, 155:166-174

58. Ascuitto RJ, Ross-Ascuitto NT: Systematic-to-pulmonary collaterals: a source of flow energy loss in Fontan physiology. Pediatr Cardiol 2004, 25:472-481.

59. Dasi LP, Pekkan K, Katajima HD, Yoganathan AP: Functional analysis of Fontan energy dissipation. J Biomech 2008 41:2246-2252.

60. Dasi LP, Pekkan K, de Zelicourt D, Sundareswaran KS, Krishnankutty R, Delnido PJ, Yoganathan AP: Hemodynamic energy dissipation in the cardiovascular system: generalized theoretical analysis on disease states. Ann Biomed Eng 2009, 37:661-673

61. Hunter KS, Lanning CJ, Chen SY, Zhang Y, Garg R, Ivy DD, Shandas R: Simulations of congenital septal defect closure and reactivity testing in patient-specific models of the pediatric pulmonary vasculature: A 3D numerical study with fluid-structure interaction. J Biomech Eng 2006, 128:564-572. 
62. Tang D, Yang C, Geva T, Rathod R, Yamauchi H, Gooty V, Tang A, Kural MH, Billiar KL, Gaudette G, et al: A Multiphysics Modeling Approach to Develop Right Ventricle Pulmonary Valve Replacement Surgical Procedures with a Contracting Band to Improve Ventricle Ejection Fraction. Computers \& structures 2013, 122:78-87.

63. Soerensen DD, Pekkan K, Sundareswaran KS, Yoganathan AP: New power loss optimized Fontan connection evaluated by calculation of power loss using high resolution PC-MRI and CFD. Conf Proc IEEE Eng Med Biol Soc 2004, 2:1144-1147.

64. Whitehead KK, Pekkan K, Kitajima HD, Paridon SM, Yoganathan AP, Fogel MA: Nonlinear power loss during exercise in single-ventricle patients after the Fontan: insights from computational fluid dynamics. Circulation 2007, 116 |165-171.

65. Eriksson J, Dyverfeldt P, Engvall J, Bolger AF, Ebbers T, Carlhall CJ: Quantification of presystolic blood flow organization and energetics in the human left ventricle. Am J Physiol Heart Circ Physiol 2011, 300:H2135-2141.

66. Fredriksson AG, Zajac J, Eriksson J, Dyverfeldt P, Bolger AF, Ebbers T, Carlhall CJ: 4-D blood flow in the human right ventricle. Am J Physiol Heart Circ Physiol 2011, 301:H2344-2350.

67. Markl M, Kilner PJ, Ebbers T: Comprehensive 4D velocity mapping of the heart and great vessels by cardiovascular magnetic resonance. J Cardiovasc Magn Reson 2011, 13:7.

68. Dyverfeldt P, Gardhagen R, Sigfridsson A, Karlsson M, Ebbers T: On MRI turbulence quantification. Magn Reson Imaging 2009, 27:913-922

69. Dyverfeldt P, Sigfridsson A, Kvitting JP, Ebbers T: Quantification of intravoxel velocity standard deviation and turbulence intensity by generalizing phase- contrast MRI. Magn Reson Med 2006, 56:850-858.

70. Carlsson M, Heiberg E, Toger J, Arheden H: Quantification of left and right ventricular kinetic energy using fourdimensional intracardiac magnetic resonance imaging flow measurements. Am J Physiol Heart Circ Physiol 2012, 302 H893-900.

71. Dyverfeldt P, Hope MD, Tseng EE, Saloner D: Magnetic resonance measurement of turbulent kinetic energy for the estimation of irreversible pressure loss in aortic stenosis. JACC Cardiovasc Imaging 2013, 6:64-71.

72. Jeong D, Roldan-Alzate A, Francois C: Right ventricular kinetic energy: 4D flow MRI analysis of healthy volunteers and repaired Tetralogy of Fallot. Journal of Cardiovascular Magnetic Resonance 2014, 16:046.

73. Lantz J, Ebbers T, Engvall J, Karlsson M: Numerical and experimental assessment of turbulent kinetic energy in an aortic coarctation. J Biomech 2013, 46:1851-1858.

74. Lee N, Taylor MD, Hor KN, Banerjee RK: Non-invasive evaluation of energy loss in the pulmonary arteries using 4D phase contrast MR measurement: a proof of concept. Biomed Eng Online 2013, 12:93.

75. Lee N, BR K, Hor K, Taylor M: Pulmonary insufficiency: Energy-Based approach using 4D Phase Contrast MRI Exp Clin Card.

76. Francois CJ, Srinivasan S, Schiebler ML, Reeder SB, Niespodzany E, Landgraf BR, Wieben O, Frydrychowicz A: 4D cardiovascular magnetic resonance velocity mapping of alterations of right heart flow patterns and main pulmonary artery hemodynamics in tetralogy of Fallot. J Cardiovasc Magn Reson 2012, 14:16.

77. Lustig M, Donoho D, Pauly JM: Sparse MRI: The application of compressed sensing for rapid MR imaging. Magn Reson Med 2007, 58:1182-1195.

78. Giese D, Wong J, Greil GF, Buehrer M, Schaeffter T, Kozerke S: Towards highly accelerated Cartesian time-resolved 3D flow cardiovascular magnetic resonance in the clinical setting. J Cardiovasc Magn Reson 2014, 16:42.

79. Jung B, Honal M, Ullmann P, Hennig J, Markl M: Highly k-t-space-accelerated phase-contrast MRI. Magn Reson Med 2008, 60:1169-1177.

80. Stalder AF, Russe MF, Frydrychowicz A, Bock J, Hennig J, Markl M: Quantitative 2D and 3D phase contrast MRI: optimized analysis of blood flow and vessel wall parameters. Magn Reson Med 2008, 60:1218-1231.

81. Frydrychowicz A, Harloff A, Jung B, Zaitsev M, Weigang E, Bley TA, Langer M, Hennig J, Markl M: Time-resolved, 3dimensional magnetic resonance flow analysis at $3 \mathrm{~T}$ : visualization of normal and pathological aortic vascular hemodynamics. J Comput Assist Tomogr 2007, 31:9-15.

82. Johnson KM, Lum DP, Turski PA, Block WF, Mistretta CA, Wieben O: Improved 3D phase contrast MRI with offresonance corrected dual echo VIPR. Magn Reson Med 2008, 60:1329-1336.

83. Markl M, Frydrychowicz A, Kozerke S, Hope M, Wieben O: 4D flow MRI. J Magn Reson Imaging 2012, 36:1015-1036.

84. Stadlbauer A, van der Riet W, Crelier G, Salomonowitz E: Accelerated time-resolved three-dimensional MR velocity mapping of blood flow patterns in the aorta using SENSE and k-t BLAST. Eur J Radiol 2010, 75:e15-21.

doi:10.1186/1475-925X-14-S1-S8

Cite this article as: Lee et al:: Right ventricle-pulmonary circulation dysfunction: a review of energy-based approach. BioMedical Engineering OnLine 2015 14(Suppl 1):S8.

\section{Submit your next manuscript to BioMed Central and take full advantage of:}

- Convenient online submission

- Thorough peer review

- No space constraints or color figure charges

- Immediate publication on acceptance

- Inclusion in PubMed, CAS, Scopus and Google Scholar

- Research which is freely available for redistribution 